\title{
International Geological Correlation Programme (IGCP) / International Geoscience Programme (IGCP)
}

\author{
http://www.unesco.org/science/earthsciences/igcp/index.htm
}

\section{General information on the IGCP}

Although many countries, especially from the developing world, share the most exciting geological features, geological structures and natural resources, research activities at various institutions are undertaken in isolation. The IGCP is unique as an international Programme that brings together several thousands of scientists from different disciplines, to stimulate dialogue and facilitate communication among

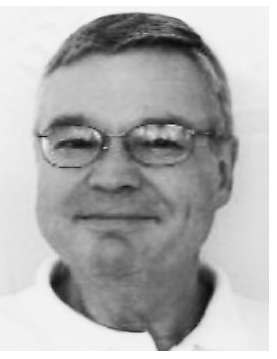

Dr Wolfgang Eder researchers throughout the world. IGCP helps to centre the interest of geoscientists on problems associated with the sustainable development of our densely populated planet, to contribute by its means to the eradication of poverty, to promote the exchange of information and communication for education, science and the constitution of a knowledge society.

The IGCP is a cooperative enterprise of the International Union of Geological Sciences (IUGS) and the United Nations Educational, Scientific and Cultural Organization (UNESCO) and has been stimulating comparative studies in the Earth Sciences since 1972. Since its inception, IGCP has made research results available to a huge number of scientists around the world in about 340 projects up to this day.

\section{IGCP's main objectives}

- Improving the understanding of geoscientific factors controlling the global environment in order that human living conditions may be improved.

- Developing more effective ways to find and assess natural resources of energy and minerals.

- Increasing the understanding of geological processes and geological concepts through correlative studies of many locations around the globe.

- Improving research standards and methods, and techniques of carrying out research.

IGCP's broad aim is to improve the management of the solid Earth by supporting activities related to fundamental and applied geosciences, with due attention being given to interactions between the geosphere, hydrosphere and biosphere. Particular efforts are made to include scientists from the developing countries, women and young scientists. The IGCP seeks to strengthen institutional and individual capacities on multidisciplinary themes related to hydrogeology, ancient ecosystems, desertification, climate change, coastal zones, environmental catastrophes, and geological heritage, among others. It also strives to improve public awareness and provides a basis for review of international and national geo-environmental policies.

\section{Selected IGCP project results}

Medical Geology, IGCP project No 454, is an example of one of the ongoing successful multidisciplinary projects. At a global scale, it brings together scientists working in developing countries

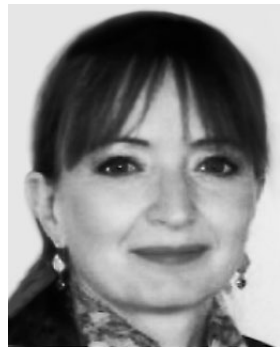

with their colleagues in other parts of the world, stressing the importance of geoscientific factors that affect the health of human beings and animals. Medical Geology is a broad and complex subject, ideally fitting in the new concept of IGCP, which requires interdisciplinary contributions from several different scientific fields. It involves joint technical meetings designed to address issues of mutual concern amongst geoscienDr Margarete Patzak tists and other disciplines (including also medical doctors and veterinarians) and holds a number of short courses in many different countries. Within the framework of the project, many individual initiatives were launched. For example, following a proposal of a member of IGCP 454, the department of Geology, Assiut University, Egypt, agreed to establish a postgraduate diploma in medical geology, which the students can join after the bachelor's degree. Another example lies in the steps that have been undertaken to lay the foundations of a medical geology research centre which will cover all South Africa.

IGCP Project 425, which started as Landslide Hazard Assessment and Cultural Heritage in 1998, ended in a culminating result as the International Consortium on Landslides (ICL) in 2003. The ICL has an international and non-governmental character, and is officially supported by UNESCO, the World Meteorological Organization (WMO), the United Nations Food and Agriculture Organization (FAO), the United Nations International Strategy for Disaster Reduction (UN/ISDR), intergovernmental programmes such as the International Hydrology Programme (IHP) of UNESCO, and governmental bodies of the United States and Japan. The Consortium has currently 33 scientific members. Its objectives, which generated from IGCP 425, are:

(1) to promote landslide research for the benefit of society and the environment, and to develop capacity-building, including education, notably in developing countries;

(2) to integrate geosciences and technology within the appropriate cultural and social contexts in order to evaluate landslide risk in urban, rural and developing areas, including cultural and natural heritage sites as well as to contribute to the protection of the natural environment and sites of high societal value;

(3) to combine and co-ordinate international expertise in landslide risk assessment and mitigation studies, thereby resulting in an effective international organization which will act as a partner in various international and national projects; and

(4) to promote a global, multidisciplinary programme on landslides.

\section{IGCP projects and funding}

IGCP works on the basis of about 40 projects annually, each of which having a life-time of 5 years. The projects are of regional and global outreach; their scope is multidisciplinary with numerous countries participating. The actual list of projects and the ones accepted in 2003 are reported in Episodes, Vol.26, No.1, March 2003. The projects encompass capacity-building components, international and regional conferences, workshops and field investigations. 
One of the great strengths of the Programme lies in the 'grass roots' origins of its projects, in their limited life span and in the IGCP's ability-through the international character of the Programme under UNESCO - to add legitimacy to research projects in a way that enables them to attract widespread, and frequently substantial, support. Most projects use the status conferred upon them by UNESCO's recognition to enhance their average 'seed money' attributed by IGCP (of about US $\$ 7,000$ per annum) from other, often national, sources by a factor ranging between 10 and 50 (in certain countries up to 200). Another strength of the Programme is the strict quality control of its projects, which are subject to rigorous annual peer review. This process is in the hands of the IGCP Scientific Board, consisting of 16 outstanding international geoscientists.

\section{IGCP Scientific Board}

A Scientific Board of 16 geoscientists is appointed by the Director-General of UNESCO and the President of IUGS. Normally, each Board Member serves for four years. The Board meets annually at UNESCO Headquarters in Paris. Its main task is to rigorously assess new IGCP project proposals and the annual reports of current projects, and to reach agreement on grading and the appropriate funding level (high, medium or low). The Board also considers broader subjects such as the policy and objectives of IGCP, and takes into account the opinions and suggestions of the IGCP National Committees. It consists of four working groups:

- Stratigraphy, Palaeontology, Sedimentology, Fossil Fuels

- Quaternary, Environmental and Engineering Geosciences

- Mineral Deposits, Petrology, Volcanology, Geochemistry

- Geophysics, Tectonics, Structural Geology.

Starting in 2004, a fifth working group task force on Hydrogeology will be added.

\section{IGCP National Committees}

At present, IGCP National Committees are established in about 100 countries acting as focal points for IGCP-related matters, in order to ensure an optimal communication with the IGCP Secretariat/Board. The level of representation, activity and size of National Committees may differ strongly from country to country. In some countries, the National Committee is composed of only one individual or of one national geological body only, while in others it has a very broad base. Ideally, the composition of the IGCP National Committee should reflect the profile of the geosciences in one country. At least, it should cover representatives from fundamental studies (generally the academia) and applied geosciences (generally the geological surveys).

\section{New directions}

IGCP has adopted a new commitment in accordance with the recommendations of Agenda 21, during the United Nations Conference on Environment and Development (UNCED) in Rio de Janeiro in 1992, and the Earth Summit +5 in New York in 1997. Greater emphasis was placed on those project proposals clearly aiming to serve the scientific needs of society by, for example, focusing on societal and cultural issues, mitigation of natural hazards, population growth and increased demand for mineral resources, water and energy, transfer of knowledge and training, and participation in the projects by scientists from developing countries.

Another discussion took place in recent years concerning the renaming of the Programme. With time, the name International Geological Correlation Programme - putting emphasis on 'correlation'-has become confusing to scientists not familiar with the new directions of the IGCP as well as for decision-makers and others. At its $29^{\text {th }}$ session, February 2001, the IGCP Scientific Board decided, in agreement with IUGS, that the Programme should be renamed the 'International Geoscience Programme', hence providing a better reflection of its current nature and purpose at the start of the twentyfirst century. The term 'Geological Correlation' which represents only one small element in the vast field of geological applications would be replaced by 'Geoscience'. 'Correlation' in the geological sense has a very restricted meaning which made sense in the early days of IGCP where focus lay indeed on the comparison in time of geological features separated in different geographical areas-the features were set to 'correlate'. Much broader than this, the term 'Geoscience' denotes the collective disciplines of geological sciences, synonymous with geology and earth sciences. It means the study of the planet Earth, the materials it is made of and the processes that act on these materials, its history and its life forms since its origin, including also hydrogeology - a discipline which will enrich the future orientation of IGCP project topics. The IGCP Board recognized the desirability of retaining the historic, widely known and respected acronym 'IGCP' and logo, together with its subtitle 'Earth Science in the Service of Society'. The renaming was endorsed by the IUGS at its Executive Committee meeting in February 2001, in Hyderabad, India and was adopted by the General Conference of UNESCO in October 2003.

\section{IGCP Secretariat}

The IGCP Secretary, which administrates the Programme, and communicates throughout the year with project leaders, IGCP National Committees and the Board Members, is located at UNESCO Headquarters in Paris. The Secretary organizes regional meetings to stimulate interest and participation in IGCP activities and prepares publications on the work of IGCP. Some of the heavy administrative work is shared with the Secretariat of IUGS in Trondheim, Norway.

\section{Publications}

IGCP regularly publishes the progress reports of its projects and the minutes of the annual sessions of the IGCP Scientific Board in an annual publication 'Geological Correlation'. This publication is free of charge and widely distributed to the geoscientific and IGCP community, IUGS, UNESCO National Commissions and interested individuals.

\section{Contact}

Dr Wolfgang Eder

IGCP Secretary

w.eder@unesco.org

Dr Margarete Patzak

IGCP Assistant Secretary

m.patzak@unesco.org

\section{IGCP website/project proposal form and guidelines}

website: http://www.unesco.org/science/earthsciences/igcp/index.htm

\section{Postal address}

IGCP

Division of Earth Sciences

UNESCO

1 , rue Miollis

75732 PARIS Cedex 15

FRANCE

Tel: (33-1) 45684118 or 26

Fax: (33-1) 45685822 